\title{
Relationships between morphological and chemical characteristics of perennial ryegrass varieties and intake by sheep under continuous stocking management
}

\author{
R. J. Orr, J. E. Cook, R. A. Champion and A. J. Rook \\ Institute of Grassland and Environmental Research, North Wyke, Okehampton, UK
}

\begin{abstract}
Plots of five intermediate-heading varieties of perennial ryegrass (Lolium perenne L.) [AberDove, Belramo and Glen (diploid); Twins (tetraploid); and AberExcel (tetraploid hybrid)] were continuously stocked with sheep to maintain a target sward surface height of 40 $50 \mathrm{~mm}$. Daily dry matter (DM) intake was significantly different $(F$-value $=0.032)$ between the varieties, with the tetraploid hybrid AberExcel having the highest values for daily DM intake and intake rate during eating. Amongst the diploid varieties, intake rate tended to be higher for sheep grazing Glen. The varieties comprised a wide range in potential growth habit, from the relatively prostrate, highly tillered Glen to the more-erect AberExcel and there were differences between them in the vertical distribution of leaves within the sward canopy. The leaves of AberExcel weighed $3.6 \mathrm{mg} \mathrm{DM} \mathrm{cm} \mathrm{cm}^{-2}$ leaf area in contrast to the other varieties $\left(4 \cdot 3-5 \cdot 3 \mathrm{mg} \mathrm{DM} \mathrm{cm}{ }^{-2}\right.$ leaf area) resulting in a high leaf area index (LAI) in relation to the green leaf mass. Intake rate was not significantly correlated with extended tiller and sheath tube lengths, partition of herbage mass, number of tillers per square metre or LAI. However, canonical variates analysis showed that there were significant differences between the varieties for the morphological and chemical factors examined. Other factors also need to be explored to explain these differences in ingestive behaviour in order to identify plant traits that are correlated with herbage intake rate. These are needed for varieties destined for grazing use, both during the breeding programme and their subsequent evaluation.
\end{abstract}

Correspondence to: R. J. Orr, Institute of Grassland and Environmental Research, North Wyke, Okehampton, Devon EX20 2SB, UK.

E-mail: robert.orr@bbsrc.ac.uk

Received 29 May 2003; revised 25 January 2004
Keywords: perennial ryegrass, intake, sward morphology, continuous stocking, sheep

\section{Introduction}

Orr et al. (2003) identified marked differences between perennial ryegrass (Lolium perenne L.) varieties in their intake characteristics when continuously stocked with sheep in a 2-year experiment. Compared with the mean in each year, the ranges in values for daily dry matter (DM) intake were proportionately $0 \cdot 81-1 \cdot 24$ in 1998 and $0 \cdot 80-1 \cdot 19$ in 1999. Intake attributes are not assessed by UK national testing procedures (Ministry of Agriculture, Fisheries and Food, 1998) for those varieties featured on the Recommended Lists (National Institute of Agricultural Botany, 1998). Evaluation procedures consider yield under simulated grazing management (measured by frequent cutting), mid-season digestibility, ground cover, winter hardiness and disease resistance. Ideally, there is a need for evaluation under grazing but Hazard et al. (1998) suggested that the use of animal trials in routine evaluation of grass cultivars under grazing was expensive and time-consuming. They indicated a need to identify morphological traits of cultivars that enhance animal production under grazing (Hodgson, 1985; Baumont et al., 2000) which could be used to evaluate grass cultivars in breeding programmes. Here it is explored whether the differences in grass intake measured by Orr et al. (2003) were related to morphological and chemical characteristics (Diaz et al., 2001; Liu et al., 2002) that could be targeted for those varieties destined for use under grazing management (Stone, 1994).

\section{Materials and methods}

\section{Sward treatments}

The experimental grazing treatments were imposed between 8 March and 9 June 2000 at the Institute of 
Grassland and Environmental Research (IGER), North Wyke $\left(50^{\circ} 46^{\prime} \mathrm{N}, 3^{\circ} 56^{\prime} \mathrm{W}\right)$.

Five intermediate-heading varieties of perennial ryegrass were chosen from the fifteen that had been sown in September 1997 and grazed by sheep in 1998 and 1999 (Orr et al., 2003) to give a wide range in intake characteristics. The varieties chosen were either diploid (AberDove, Belramo and Glen), tetraploid (Twins) or tetraploid hybrid (Lolium $\times$ boucheanum Kunth) (AberExcel). Fertilizer supplying $40 \mathrm{~kg} \mathrm{~N} \mathrm{ha}^{-1}, 20 \mathrm{~kg}$ $\mathrm{P}_{2} \mathrm{O}_{5} \mathrm{ha}^{-1}$ and $20 \mathrm{~kg} \mathrm{~K}_{2} \mathrm{O} \mathrm{ha}^{-1}$ was applied to the swards on 30 March 2000, followed by an application of $40 \mathrm{~kg} \mathrm{~N} \mathrm{ha}^{-1}$ on 5 May 2000.

\section{Animals and grazing management}

Core groups of three non-pregnant, non-lactating (dry) Welsh Mountain ewes [live weight (s.e. of mean), 33 $(0 \cdot 2) \mathrm{kg}$ ] were continuously stocked on the same five replicate paddocks $(0 \cdot 1 \mathrm{ha})$ of each grass variety that were grazed in 1998 and 1999 (i.e. the third grazing year for each paddock). Each core group comprised one ewe aged 2 years and two ewes aged 3 years.

A target sward surface height (SSH) of $40-50 \mathrm{~mm}$ was maintained on each of the twenty-five paddocks using a put-and-take system, with additional ewes added to or removed from the paddocks as required.

\section{Measurements}

\section{Morphological measurements}

Sward surface height was measured each week using a sward stick (Barthram, 1986), with twenty-five contacts per paddock. Herbage measurements were made on each of the five blocks in succession on 23 and 24 May; 24 and 25 May; 30 and 31 May; 31 May and 1 June; 1 and 2 June. Herbage mass, composition and the number of tillers per square metre were measured within $50 \mathrm{~cm} \times 25 \mathrm{~cm}$ quadrats. The herbage was cut to ground level using scalpels and sub-samples of grass were separated into live leaves, live vegetative and reproductive stems, and dead material. Reproductive tillers in the subsample were identified on the basis of internode elongation and the numbers of both reproductive and vegetative tillers in the subsample were counted. The dry weight (oven-drying at $80^{\circ} \mathrm{C}$ for $20 \mathrm{~h}$ ) of the components and the number of tillers were calculated from the contribution of their weight to the total weight of the respective subsamples and the total sample weight.

Extended tiller lengths (ETL) and sheath tube lengths of the youngest and oldest fully expanded live leaves were measured on all the tillers in each subsample (approximately sixty tillers per paddock). LAI (leaf area per unit ground area) was measured by passing leaves from these tillers through a planimeter before they were dried, which allowed dry weights per unit leaf area to be calculated.

The vertical distribution of leaves within the swards was estimated using an inclined point quadrat (IPQ) as described by Grant (1981). This device works by passing a needle from the surface of the sward, at an angle of $32.5^{\circ}$, down to the soil level. This angle was determined (Warren Wilson, 1963) from consideration of the grass foliage angle (inclination of foliage to the horizontal). Turves $(10 \mathrm{~cm} \times 20 \mathrm{~cm})$ were cut, taken indoors and placed on a bench where the measurements were made. Twenty-five descents were made on each variety and each contact with leaves was recorded from a graduated scale so that the height above ground level could be calculated by trigonometry.

Daily intake, eating time, intake rate and ruminating time

Grass intake was measured using a modification of the $n$-alkane method of Dove and Mayes (1991). The three core sheep in each paddock were dosed with Captec ${ }^{\mathrm{TM}}$ n-alkane slow-release devices (FERNZ, Manurewa, Auckland, New Zealand). Following an initial acclimatization period, the boluses were designed to release $\mathrm{C}_{32}$-alkane (dotriacontane) within the rumen at a constant rate between days 8 and 16 after dosing. Eight days after dosing, any spare ewes were removed for $48 \mathrm{~h}$ and marked areas $(15 \mathrm{~m} \times 2 \mathrm{~m})$ within each paddock were cleared of all faeces. This was done on 23, 25 and 31 May, 1 and 7 June for the five replicate blocks in succession. Faeces samples were collected, from within the cleared areas, 24 and $48 \mathrm{~h}$ after clearing. This procedure ensured that only samples from dosed animals were collected.

Herbage samples (snipped samples), designed to be representative of the material eaten, were cut with scissors from the grazed horizon in the top third of the sward (Orr et al., 1997) at the same time as the initial faeces clearance. Mean daily DM intake by the group was calculated from the assayed release rate of $\mathrm{C}_{32}-$ alkane $\left(44.9 \mathrm{mg} \mathrm{d}^{-1}\right)$ and the concentrations of $\mathrm{C}_{32^{-}}$ and $\mathrm{C}_{33}$-alkane (tritriacontane) in herbage and faeces (Dove and Mayes, 1991).

Jaw movements were recorded over $24 \mathrm{~h}$ for one core ewe on each of the twenty-five paddocks, using automatic behaviour recorders (Rutter et al., 1997). Recordings were subsequently analysed using the GRAZE $^{\mathrm{TM}}$ software (Rutter, 2000) to distinguish periods of eating, ruminating and idling and thus allow the calculation of eating time (Gibb, 1998). Intake rate during eating was calculated from intake $\left(\mathrm{g} \mathrm{DM} \mathrm{d}^{-1}\right)$ and eating time $\left(\operatorname{min~}^{-1}\right)$. Rumination chews were 
identified, and the number of chews per minute and per bolus were calculated.

Data for eating time and ruminating time included pauses of $<3 \mathrm{~s}$ between successive jaw movements (i.e. the minimum inter-bout interval was 3 s) and an eating bout and a ruminating bout each contained at least ten jaw movements. Jaw movements that did not satisfy these criteria were broadly designated as 'other activities' e.g. drinking, grooming, vocalization, etc. The patterns of meals throughout the day were examined by joining eating bouts with a minimum inter-meal interval of 6 min (Penning et al., 1993) to create grazing bouts as defined by Gibb (1998), which included intrameal intervals of $\geq 3 \mathrm{~s}-6 \mathrm{~min}$ duration. Individual rumination bouts associated with the eructation of each bolus were joined using a minimum inter-rumination bout interval of $20 \mathrm{~s}$.

\section{Chemical analyses}

The snipped grass samples were analysed for digestibility of organic matter in the DM (DOMD in vitro; Jones and Haywood, 1975), for nitrogen (N) concentration by the Kjeldahl method, with copper sulphate as a catalyst, using a Tecator 1030 auto analyser (Tecator, 1987) and for water-soluble carbohydrate (WSC) concentration (Thomas, 1977).

\section{Statistical analysis}

The group of three core ewes was used as the experimental unit for statistical analysis of animal variables (i.e. all the analyses were based on $n=25$, with sixteen residual d.f. as the five treatments were allocated to five blocks) as the behaviour and performance of the individuals were not regarded as independent (Rook and Penning, 1991). Data were analysed by one-way analysis of variance with randomised blocks using GENSTAT (GENSTAT, 1987). In addition to the overall effect of variety, the effects of ploidy (diploid vs. tetraploid) and hybridisation (tetraploid vs. tetraploid hybrid) were also examined using orthogonal contrasts (see Tables 1-3). Correlation analyses between ingestive behaviour and plant factors were performed using values for individual plots (i.e. $n=25$ ). Canonical variates analysis, using the CVA directive in GENSTAT, was used to find linear combinations of the original variables that maximized the ratio of between-variety to within-variety variation, thereby giving functions of the original variables that could be used to discriminate between the varieties. The CVAPLOT procedure was then used to plot the mean scores of the first two latent vectors of the canonical variates analysis and to display $95 \%$ confidence limits. Dendrograms were plotted of levels of similarity between the varieties using

Table I Grass morphology and chemical composition for diploid and tetraploid perennial ryegrass varieties continuously stocked with sheep.

\begin{tabular}{|c|c|c|c|c|c|c|c|c|c|}
\hline & \multicolumn{3}{|c|}{ Diploid } & \multicolumn{2}{|c|}{ Tetraploid } & \multicolumn{4}{|c|}{$F$ probability } \\
\hline & AberDove & Belramo & Glen & AberExcel $\dagger$ & Twins & s.e.d. & Overall & Ploidy & Hybridisation \\
\hline \multicolumn{10}{|l|}{ Morphological factors } \\
\hline $\mathrm{SSH}(\mathrm{mm})$ & $46 \cdot 7$ & $48 \cdot 9$ & $45 \cdot 2$ & $45 \cdot 1$ & $45 \cdot 4$ & $2 \cdot 62$ & $0 \cdot 579$ & $0 \cdot 332$ & 0.928 \\
\hline ETL $(\mathrm{mm})$ & $54 \cdot 3$ & $50 \cdot 8$ & $50 \cdot 4$ & $61 \cdot 6$ & $52 \cdot 0$ & $4 \cdot 71$ & $0 \cdot 171$ & $0 \cdot 129$ & 0.062 \\
\hline ETL:SSH ratio & $1 \cdot 16$ & $1 \cdot 04$ & $1 \cdot 12$ & $1 \cdot 37$ & $1 \cdot 15$ & $0 \cdot 104$ & $0 \cdot 169$ & $0 \cdot 126$ & $0 \cdot 111$ \\
\hline \multicolumn{10}{|l|}{ Sheath tube length $(\mathrm{mm})$} \\
\hline Oldest fully expanded live leaf & $14 \cdot 7$ & $15 \cdot 2$ & $13 \cdot 8$ & $16 \cdot 6$ & $13 \cdot 3$ & $2 \cdot 32$ & $0 \cdot 647$ & $0 \cdot 827$ & $0 \cdot 171$ \\
\hline Youngest fully expanded live leaf & $23 \cdot 8$ & $25 \cdot 0$ & $20 \cdot 7$ & $28 \cdot 4$ & $20 \cdot 2$ & $3 \cdot 61$ & $0 \cdot 195$ & $0 \cdot 619$ & $0 \cdot 037$ \\
\hline Leaf mass ( $\mathrm{kg} \mathrm{DM} \mathrm{ha}^{-1}$ ) & 1321 & 905 & 1307 & 1216 & 1242 & $176 \cdot 4$ & $0 \cdot 169$ & $0 \cdot 655$ & $0 \cdot 882$ \\
\hline Pseudostem $\left(\mathrm{kg} \mathrm{DM} \mathrm{ha}^{-1}\right)$ & 1289 & 1151 & 1046 & 1109 & 872 & $156 \cdot 7$ & $0 \cdot 159$ & $0 \cdot 109$ & $0 \cdot 149$ \\
\hline Leaf:pseudostem ratio & $1 \cdot 05$ & $0 \cdot 78$ & $1 \cdot 30$ & $1 \cdot 15$ & $1 \cdot 41$ & $0 \cdot 181$ & $0 \cdot 027$ & $0 \cdot 056$ & $0 \cdot 163$ \\
\hline Tillers (in thousands $\mathrm{m}^{-2}$ ) & $39 \cdot 7$ & $31 \cdot 1$ & $43 \cdot 2$ & $31 \cdot 1$ & $25 \cdot 7$ & $7 \cdot 18$ & $0 \cdot 149$ & $0 \cdot 055$ & $0 \cdot 461$ \\
\hline Leaf weight (mg DM cm $\mathrm{cm}^{-2}$ leaf area) & $4 \cdot 4$ & $4 \cdot 6$ & $4 \cdot 3$ & $3 \cdot 6$ & $5 \cdot 3$ & $0 \cdot 65$ & $0 \cdot 172$ & $0 \cdot 950$ & $0 \cdot 017$ \\
\hline Leaf area index & $3 \cdot 1$ & $2 \cdot 0$ & $3 \cdot 2$ & $3 \cdot 5$ & $2 \cdot 6$ & 0.73 & $0 \cdot 292$ & 0.521 & $0 \cdot 217$ \\
\hline \multicolumn{10}{|l|}{ Chemical factors } \\
\hline WSC ( $\left.\mathrm{g} \mathrm{kg}^{-1} \mathrm{DM}\right)$ & 213 & 177 & 193 & 186 & 249 & $19 \cdot 0$ & $0 \cdot 012$ & $0 \cdot 077$ & $0 \cdot 004$ \\
\hline DOMD (g DOM kg ${ }^{-1}$ DM) & 735 & 711 & 720 & 719 & 745 & $7 \cdot 4$ & $0 \cdot 002$ & $0 \cdot 047$ & 0.003 \\
\hline Nitrogen $\left(\mathrm{g} \mathrm{kg}^{-1} \mathrm{DM}\right)$ & 40 & 40 & 38 & 44 & 37 & $2 \cdot 6$ & $0 \cdot 138$ & $0 \cdot 681$ & $0 \cdot 017$ \\
\hline
\end{tabular}

†Hybrid.

DM, dry matter; DOMD, organic matter in the DM; ETL, Extended tiller length; SSH, Sward surface height; WSC, water-soluble carbohydrate. 
Table 2 Daily intake, eating time and intake rate for sheep continuously stocked on diploid and tetraploid ryegrass varieties.

\begin{tabular}{|c|c|c|c|c|c|c|c|c|c|}
\hline & \multicolumn{3}{|c|}{ Diploid } & \multicolumn{2}{|c|}{ Tetraploid } & \multirow[b]{2}{*}{ s.e.d. } & \multicolumn{3}{|c|}{$F$ probability } \\
\hline & AberDove & Belramo & Glen & AberExcel† & Twins & & Overall & Ploidy & Hybridisation \\
\hline Daily intake (g DM ewe ${ }^{-1}$ ) & 603 & 765 & 734 & 904 & 616 & $93 \cdot 4$ & $0 \cdot 032$ & $0 \cdot 345$ & $0 \cdot 007$ \\
\hline Eating time $\left[\min (24 \mathrm{~h})^{-1}\right)$ & 616 & 707 & 642 & 664 & 628 & $61 \cdot 6$ & $0 \cdot 619$ & $0 \cdot 818$ & 0.576 \\
\hline Intake rate ( $\mathrm{mg} \mathrm{DM} \min ^{-1}$ eating) & 978 & 1089 & 1165 & 1390 & 1004 & $188 \cdot 8$ & $0 \cdot 239$ & $0 \cdot 340$ & $0 \cdot 057$ \\
\hline Number of meals $\left(24 \mathrm{~h}^{-1}\right)$ & $7 \cdot 4$ & $5 \cdot 8$ & $7 \cdot 2$ & $7 \cdot 6$ & $7 \cdot 2$ & $1 \cdot 60$ & $0 \cdot 810$ & $0 \cdot 571$ & $0 \cdot 806$ \\
\hline Meal duration (h) & $1 \cdot 73$ & $2 \cdot 43$ & $1 \cdot 67$ & 1.85 & $1 \cdot 69$ & $0 \cdot 484$ & 0.503 & $0 \cdot 592$ & $0 \cdot 747$ \\
\hline
\end{tabular}

†Hybrid.

Table 3 Ruminating time, number of boluses per 24 h, chews per 24 h, chews per minute and chews per bolus for sheep continuously stocked on diploid and tetraploid ryegrass varieties.

\begin{tabular}{|c|c|c|c|c|c|c|c|c|c|}
\hline & \multicolumn{3}{|c|}{ Diploid } & \multicolumn{2}{|c|}{ Tetraploid } & \multirow[b]{2}{*}{ s.e.d. } & \multicolumn{3}{|c|}{$F$ probability } \\
\hline & AberDove & Belramo & Glen & AberExcel† & Twins & & Overall & Ploidy & Hybridisation \\
\hline Ruminating time $\left(\min 24 \mathrm{~h}^{-1}\right)$ & 332 & 387 & 304 & 350 & 278 & $47 \cdot 7$ & $0 \cdot 242$ & $0 \cdot 397$ & $0 \cdot 154$ \\
\hline Number of boluses $\left(24 \mathrm{~h}^{-1}\right)$ & 451 & 489 & 418 & 470 & 422 & $54 \cdot 6$ & $0 \cdot 650$ & $0 \cdot 844$ & $0 \cdot 390$ \\
\hline Ruminating chews $\left(24 \mathrm{~h}^{-1}\right)$ & 26047 & 30937 & 24561 & 29536 & 21348 & $5412 \cdot 4$ & $0 \cdot 429$ & $0 \cdot 625$ & $0 \cdot 150$ \\
\hline Ruminating chews $\left(\min ^{-1}\right)$ & $77 \cdot 1$ & $79 \cdot 6$ & $80 \cdot 0$ & $83 \cdot 4$ & $74 \cdot 8$ & $6 \cdot 74$ & $0 \cdot 764$ & $0 \cdot 971$ & $0 \cdot 221$ \\
\hline Ruminating chews (bolus ${ }^{-1}$ ) & $56 \cdot 7$ & $63 \cdot 6$ & $57 \cdot 9$ & $62 \cdot 5$ & $48 \cdot 9$ & $7 \cdot 33$ & $0 \cdot 322$ & $0 \cdot 443$ & $0 \cdot 082$ \\
\hline
\end{tabular}

†Hybrid.

hierarchical clustering procedures in GENSTAT. The IPQ data were analysed by fitting asymmetrical s-shaped curves for each paddock and from analysis of variance on the inflection points and upper asymptotes.

\section{Results}

\section{Morphological traits}

Mean sward surface height (Table 1) when the measurements of intake were made was within the target range of $40-50 \mathrm{~mm}$ for all five varieties. Within the tetraploid varieties, extended tiller length tended to be greater $(P=0.062)$ for AberExcel (hybrid) than Twins. The ratio of extended tiller length to sward surface height, along with sheath tube lengths of the oldest and youngest fully expanded live leaves, tended to be greater for AberExcel than the other varieties but these trends were not significant between the five varieties. Within the tetraploid varieties, the length of the sheath tube of the youngest fully expanded leaf was greater $(P=0.037)$ for AberExcel than Twins $(28.4 \mathrm{~mm}$ vs. $20 \cdot 2 \mathrm{~mm})$ at the same sward surface height.

The mean number of IPQ leaf contacts in each horizon is shown in Figure 1. Above $40 \mathrm{~mm}$ from the root-shoot interface, the variety AberExcel, in particular, together with the Glen and AberDove varieties, had more contacts than the Twins and Belramo variety. The variety Glen tended to have most leaf contacts in total and the variety Belramo had the least, but these effects were not significant.

Leaf and pseudostem masses, and the number of grass tillers per square metre, were not significantly different between the five varieties, although Belramo had a much lower green leaf mass (Table 1). Leaf:pseudostem ratios were significantly different $(P=0.027)$ between the five varieties and tended to be higher $(P=0.056)$ for the tetraploid than the diploid varieties.

The swards were all very highly tillered, particularly the diploid variety Glen, as a result of the continuous stocking management with sheep. Comparing the effects of ploidy, the diploid varieties tended $(P=$ $0.055)$ to have greater numbers of tillers per square metre than the tetraploid varieties. Within the tetraploid varieties, the leaves of AberExcel had significantly lower $(P=0.017)$ weights per unit leaf area than Twins

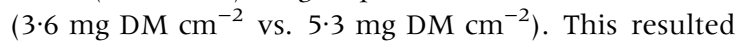
in the variety AberExcel tending to have a high LAI in relation to the green leaf mass.

\section{Chemical composition}

There were significant differences between varieties (Table 1) in water-soluble carbohydrate concentration $(P=0.012)$ and DOMD value $(P=0.002)$ but not in $\mathrm{N}$ concentration. The tetraploid varieties had significantly higher DOMD values $(P=0 \cdot 047)$ than the diploids and, within the tetraploid varieties, Twins had a significantly 


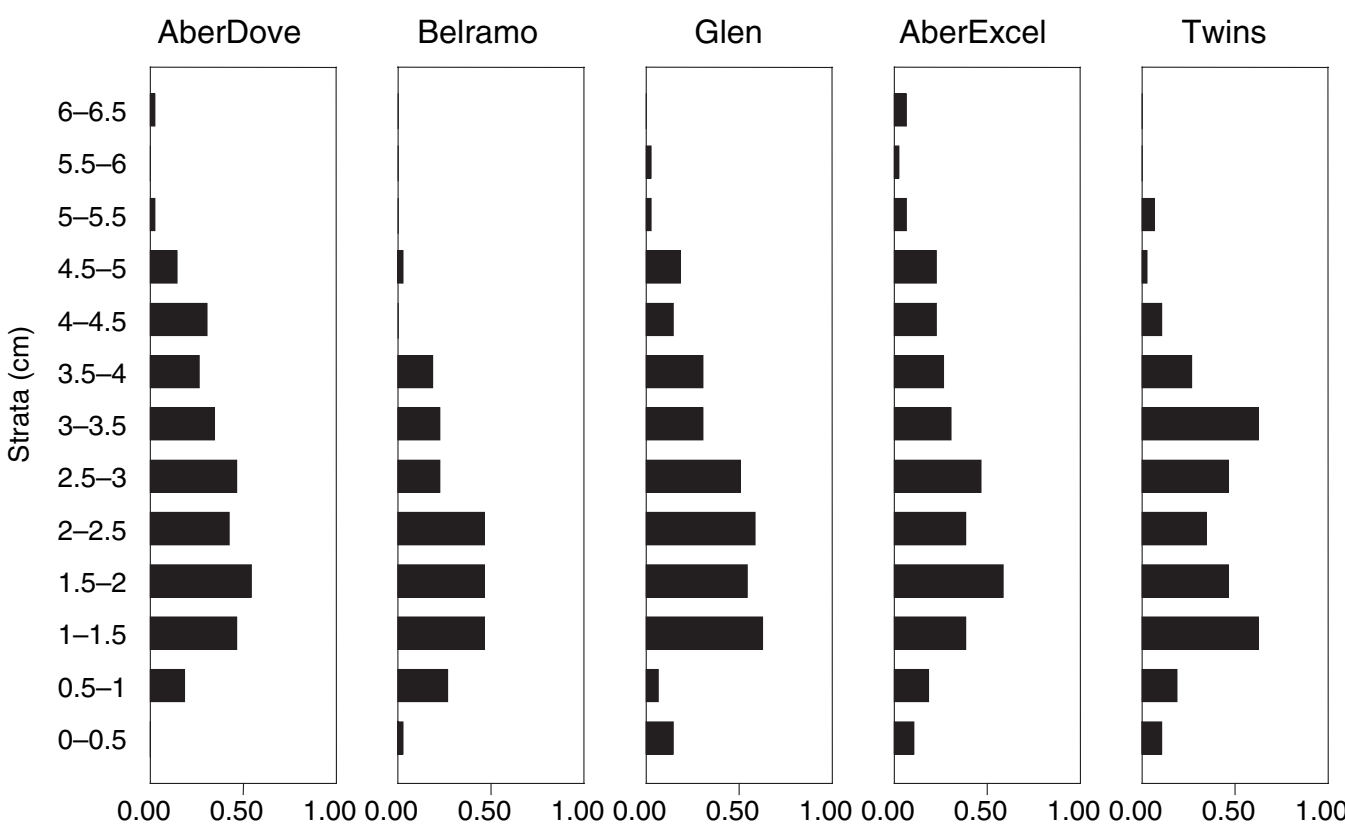

No. of leaf contacts per descent in $0.5 \mathrm{~cm}$ strata above ground level

Figure I Number of leaf contacts per descent in $0.5 \mathrm{~mm}$ strata above ground level for perennial ryegrass varieties grazed by sheep.

higher DOMD value $(P=0 \cdot 003)$, higher WSC concentration $(P=0.004)$ and lower $\mathrm{N}$ concentration $(P=$ 0.017) than AberExcel.

\section{Daily intake, eating time and intake rate}

Daily DM intake (Table 2) was significantly different $(P=0.032)$ between the varieties. Within the tetraploid varieties daily intake was higher $(P=0.007)$ for ewes grazing AberExcel than for those grazing Twins, and intake rate also tended to be higher $(P=0.057)$. Eating time was not significantly different between the five varieties [mean: $652 \mathrm{~min}\left(24 \mathrm{~h}^{-1}\right)$ ]. Examination of the patterns of meals for individual ewes made on each of the five replicate paddocks for each variety indicated that most of the grazing occurred between sunrise $(05: 00 \mathrm{~h})$ and sunset $(21: 45 \mathrm{~h})$. Whilst the number of meals per day tended to be lower on the variety Belramo and the meal duration tended to be greater than on the other varieties, these were not significant (Table 2).

\section{Ruminating time, boluses and chews}

The variety Belramo tended to have the highest values for all the aspects of rumination behaviour (except rumination chewing rate) shown in Table 3 and the variety Twins had the lowest values (except for the number of boluses per $24 \mathrm{~h}$, for which the value was close to that for the variety Glen which was the lowest), but these differences were not significant. The period following sunset (and the cessation of the evening meal) until approximately 09:00 h was characterized by alternating bouts of rumination and rest on all five varieties. There was some further processing of ingested grass interspersed between eating bouts, particularly in the late morning/early afternoon period, but the period before sunset (approximately $4 \mathrm{~h}$ ) was mainly occupied by eating.

\section{Canonical variates analysis}

The canonical variates analysis for the plant factors are summarized in Figure 2a where the mean scores for latent vector 1 and latent vector 2 are plotted, along with the $95 \%$ confidence limits. The plant factors included were those listed in Table 1. The variation accounted for by latent vectors 1,2 and 3 was $62.7,28.5$ and $5.6 \%$ respectively. The analysis clearly separated the tetraploid varieties from the diploid varieties. AberExcel differed from the other varieties in latent vector 1 score, which had a high loading for leaf:stem ratio and $\mathrm{N}$ concentration. Twins differed from the other varieties in latent vector 2 

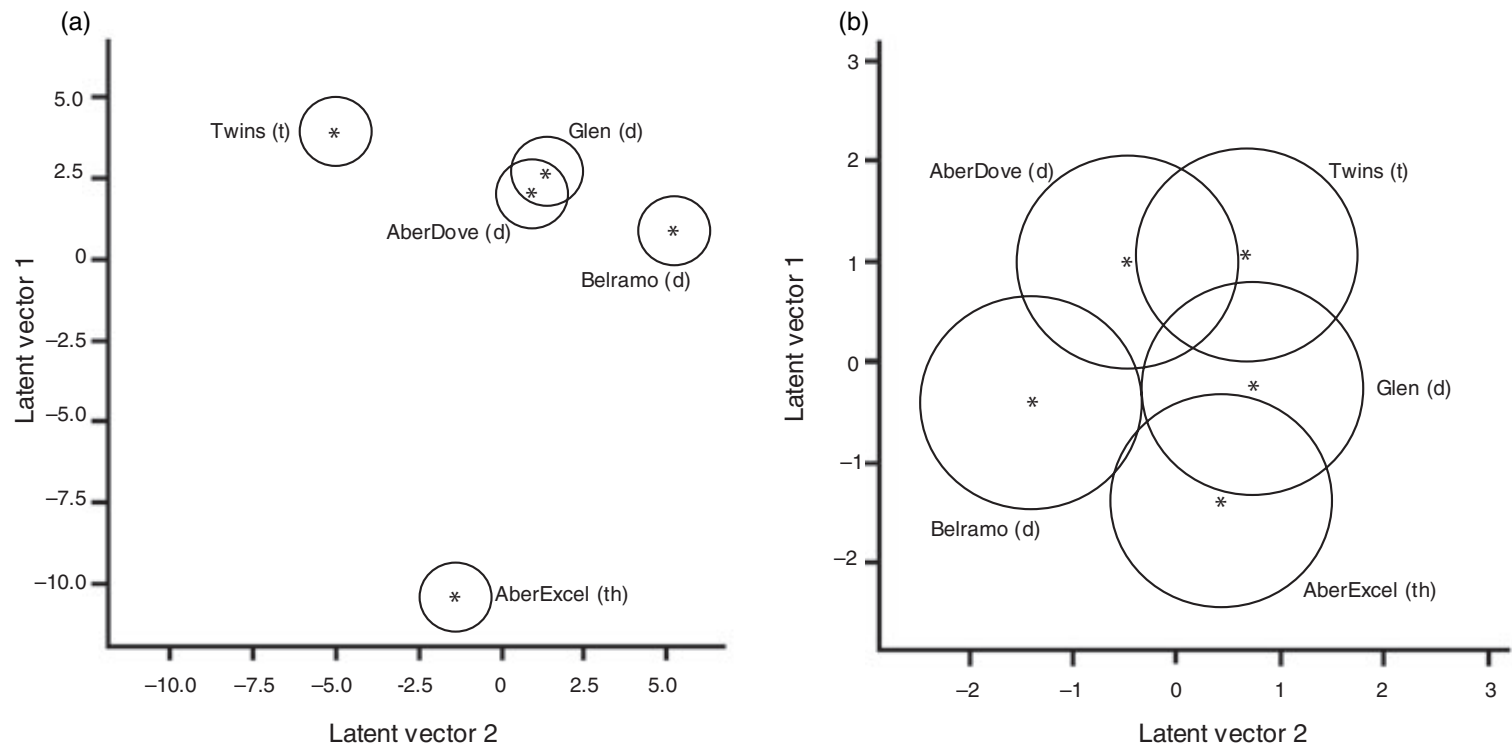

(c)

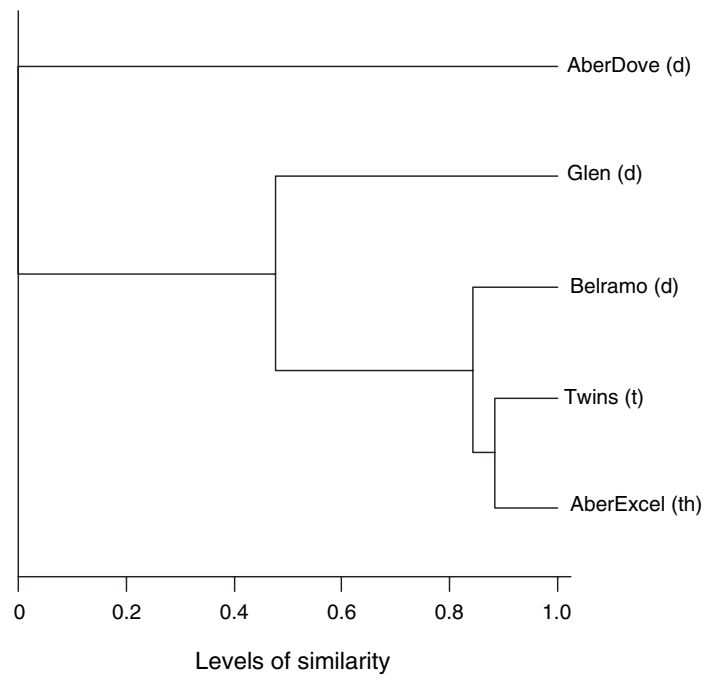

(d)

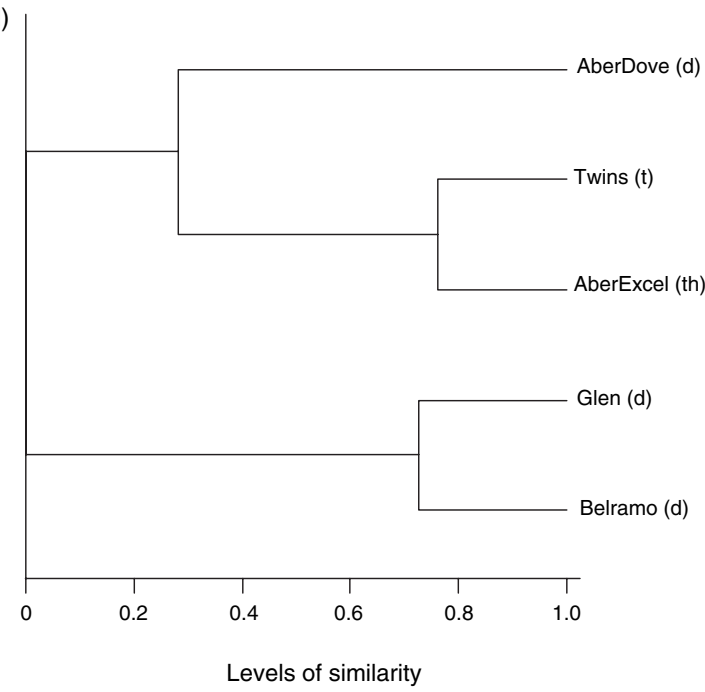

Figure 2 Canonical variates plot of (a) combined plant morphological factors: sward surface height, extended tiller length, sheath tube lengths for the oldest and youngest fully expanded live leaves, total, green leaf and pseudostem masses, leaf:pseudostem ratio, number of tillers per square metre, leaf area index, leaf weight, digestibility (DOMD), nitrogen and water-soluble carbohydrate concentrations; (b) combined ingestion and rumination factors: intake rate, daily intake, eating and ruminating times, rumination chews per minute and per bolus. Dendrograms showing levels of similarity between varieties for (c) morphological factors and (d) ingestion/rumination factors. '*', mean score for each variety; 'o' indicate 95\% confidence regions. $d$, diploid; t, tetraploid; th, tetraploid hybrid varieties.

score, which had a high loading for LAI and leaf weight per unit leaf area. Leaf:stem ratio also had a high loading for latent vector 3 (not shown in Figure 2).

The canonical variates plot of animal factors related to ingestion and rumination are shown in Figure $2 \mathrm{~b}$. The separation between the varieties was not as marked as for the plant factors (Figure 2a). The variation accounted for by latent vectors 1,2 and 3 was $52 \cdot 7,41.9$ and $3.9 \%$ respectively. Daily DM intake had the highest loading for latent vectors 1 and 2. Intake rate had a high loading for latent vector 2 . 
The dendrogram of plant factors, using information on all latent vector dimensions available, is shown in Figure 2c. As might be expected, there were close similarities between Twins and AberExcel, the tetraploid varieties. There were lesser similarities between these varieties and Belramo and Glen. AberDove did not cluster with the other varieties for plant factors. This diploid variety was only clustered with the two tetraploid varieties for animal factors (Figure 2d) at a low level of similarity. Glen and Belramo (diploids) were clustered for animal factors, as were Twins and Excel (tetraploids).

\section{Correlations between plant and animal factors}

Intake rate was not correlated with sward height, mass, sheath tube lengths or the other sward measurements shown in Table 4. Daily DM intake was not significantly correlated with eating time but was correlated with intake rate $(r=0.86 ; P<0.001)$. This was to be expected as intake rate was calculated from daily intake, but the lack of correlation with eating time is worth noting.

Ruminating time was positively correlated with $\mathrm{N}$ concentration in grass $(r=0.45 ; P<0.05)$ and negatively correlated with WSC concentration $(r=-0.53$; $P<0.05)$. Concentrations of WSC and $\mathrm{N}$ in herbage were negatively correlated $(r=-0.82 ; P<0.001)$.

\section{Discussion}

\section{Morphological factors}

Continuous stocking with sheep to maintain the SSH within target guidelines was intended to optimise sward and animal performance (Parsons, 1984) when the swards became adapted to this management (Penning et al., 1991) in terms of tillering and leaf mass. The five varieties embraced a wide range in growth habit from the relatively prostrate, highly tillered Glen to the more-erect tetraploid hybrid AberExcel. In the present experiment, when all the swards were managed to maintain a SSH of $40-50 \mathrm{~mm}$, there were still contrasts in leaf:pseudostem ratio (Table 1). Swift et al. (1993) compared a late-heading diploid (Contender) with a tetraploid (Condesa) perennial ryegrass variety under continuous stocking with ewes and lambs and measured tiller densities of 17900 and 12200 tillers $\mathrm{m}^{-2}$, respectively, on average over 3 years. Mean values in May for diploid and tetraploid varieties in the current experiment were somewhat higher at 38000 and 28400 tillers $\mathrm{m}^{-2}$ respectively. Tillering will be affected by management and environmental constraints (Neuteboom and Lantinga, 1989; Gautier et al., 1999) but, while there may be some overlap in the number of tillers per square metre for individual diploid and tetraploid varieties at points in time during the grazing

Table 4 Correlation matrix showing relationships between intake rate and sward parameters.

\begin{tabular}{|c|c|c|c|c|c|c|c|c|c|c|c|c|c|c|}
\hline & ir & & & & & & & & & & & & & \\
\hline SSH & $0 \cdot 28$ & $\mathrm{SSH}$ & & & & & & & & & & & & \\
\hline ETL & $0 \cdot 16$ & $0 \cdot 37$ & ETL & & & & & & & & & & & \\
\hline Old & 0 & 0 & 0.61 & Old & & & & & & & & & & \\
\hline Young & $0 \cdot 13$ & -0.08 & 0.59 & $0 \cdot 81$ & Young & & & & & & & & & \\
\hline Mass & -0.08 & $0 \cdot 40$ & $0 \cdot 44$ & $0 \cdot 16$ & $0 \cdot 04$ & Mass & & & & & & & & \\
\hline Leaf & $0 \cdot 09$ & $0 \cdot 36$ & 0.38 & $-0 \cdot 22$ & $-0 \cdot 17$ & 0.78 & Leaf & & & & & & & \\
\hline Stem & $0 \cdot 06$ & $0 \cdot 34$ & 0.52 & $0 \cdot 51$ & $0 \cdot 49$ & 0.68 & 0.32 & Stem & & & & & & \\
\hline 1:s ratio & 0.05 & $0 \cdot 04$ & $-0 \cdot 08$ & $-0 \cdot 62$ & -0.54 & 0.08 & 0.59 & $-0 \cdot 57$ & l:s ratio & & & & & \\
\hline Tillers & $0 \cdot 13$ & $-0 \cdot 28$ & $-0 \cdot 17$ & $0 \cdot 02$ & $0 \cdot 12$ & 0.38 & $0 \cdot 28$ & $0 \cdot 43$ & $-0 \cdot 14$ & Tillers & & & & \\
\hline LAI & $0 \cdot 18$ & $0 \cdot 41$ & 0.61 & $0 \cdot 16$ & $0 \cdot 11$ & 0.76 & 0.84 & $0 \cdot 38$ & $0 \cdot 40$ & $0 \cdot 18$ & LAI & & & \\
\hline Leaf $w t$ & $-0 \cdot 16$ & $-0 \cdot 22$ & $-0 \cdot 50$ & $-0 \cdot 41$ & $-0 \cdot 33$ & $-0 \cdot 42$ & $-0 \cdot 29$ & $-0 \cdot 29$ & 0 & $-0 \cdot 07$ & $-0 \cdot 72$ & Leaf wt & & \\
\hline DOMD & $-0 \cdot 28$ & $0 \cdot 01$ & $-0 \cdot 21$ & -0.56 & -0.65 & -0.08 & $0 \cdot 18$ & $-0 \cdot 46$ & $0 \cdot 56$ & $-0 \cdot 40$ & -0.07 & 0.32 & DOMD & \\
\hline $\mathrm{N}$ & $0 \cdot 25$ & $0 \cdot 37$ & 0 & $-0 \cdot 13$ & 0 & $-0 \cdot 15$ & 0 & $-0 \cdot 13$ & $0 \cdot 11$ & $-0 \cdot 24$ & $0 \cdot 07$ & -0.06 & $0 \cdot 10$ & $\mathrm{~N}$ \\
\hline WSC & -0.32 & $-0 \cdot 34$ & 0 & $-0 \cdot 14$ & -0.23 & 0.06 & 0.08 & $-0 \cdot 17$ & $0 \cdot 23$ & $-0 \cdot 12$ & -0.09 & $0 \cdot 19$ & $0 \cdot 39$ & $-0 \cdot 82$ \\
\hline
\end{tabular}

$|r|>0.43, P<0.05 ;|r|>0.55, P<0.01 ;|r|>0.67, P<0.001$.

ir, intake rate (mg DM min $^{-1}$ eating); SSH, sward surface height $(\mathrm{mm})$; ETL, extended tiller length (mm); old and young, sheath tube lengths for the oldest and youngest fully expanded live leaves $(\mathrm{mm})$; mass, weight of dry matter; leaf, weight of green leaves; stem, weight of pseudostems ( $\mathrm{kg} \mathrm{DM} \mathrm{ha}^{-1}$ ); l:s, leaf weight:stem weight ratio; tillers, number of tillers per square metre; LAI, leaf area index (leaf area per unit ground area); leaf $\mathrm{wt},\left(\mathrm{mg} \mathrm{DM} \mathrm{cm}{ }^{-2}\right.$ leaf area); DOMD, digestibility (g DOM kg $\left.{ }^{-1} \mathrm{DM}\right) ; \mathrm{N}, \mathrm{nitrogen}$ concentration $\left(\mathrm{g} \mathrm{kg}^{-1} \mathrm{DM}\right)$; WSC, water-soluble carbohydrate concentration $\left(\mathrm{g} \mathrm{kg}^{-1} \mathrm{DM}\right)$ for sheep grazing perennial ryegrass varieties (19 d.f.). 
season, it is generally the case that tiller density tends to be higher for diploid varieties than for tetraploids (Smith et al., 2001). Previously, Orr et al. (2003) found that the mean tiller densities over the grazing season for perennial ryegrass varieties grazed by sheep in 1998 and 1999 were 24000 (diploids), 17800 (tetraploids) and 17100 tillers $\mathrm{m}^{-2}$ (tetraploid hybrids). A feature of the hybrid varieties is the influence of Italian ryegrass (Lolium multiflorum L.) and its inherent early season growth combined with the sward density attributes of perennial ryegrass.

Stratified clipping methods for measuring the vertical distribution of herbage mass were described by Barthram et al. (2000). Schulte and Lantinga (2002) suggested structure was an important feature affecting grazing. They modelled sward vertical structure and predicted the leaf profile and lamina density profile of perennial ryegrass from the average leaf length, the sheath tube length and either herbage mass or LAI. Barthram and Grant (1984) suggested that the different frequencies of grazing of the different classes of laminae in perennial ryegrass swards grazed by sheep could be interpreted as being a function of their frequency of occurrence within the grazed layer at the top of the sward. Orr et al. (2004) measured intake and plant factors every 2-3 d for rotationally stocked yearling dairy heifers grazing down perennial ryegrass pastures over two to three weekly periods. Sheath tube and leaf length measurements appeared to be useful traits that could be used to breed plants more suitable for grazing animals, i.e. to take account of intake characteristics. Bite mass was correlated with the lengths of the second and third oldest live leaves, along with the sheath tube length of the third oldest leaf as the swards were grazed down. Leaf lengths were not measured in the current experiment and intake rate was not correlated with sheath tube lengths in the continuous stocking conditions where sward state remained constant.

\section{Chemical factors}

There were significant differences between varieties in DOMD and WSC concentration (Table 1). Data have been reported previously on DOMD and N concentration in grass snips (Orr et al., 2001) and on WSC concentration (Orr et al., 2003) for these five varieties when grazed by sheep under continuous stocking management in 1998 and 1999. The highest mean N concentrations in grass snips taken over the grazing season were measured in AberExcel in 1998 and 1999 (45.1 $\left.\mathrm{g} \mathrm{N} \mathrm{kg}^{-1} \mathrm{DM}\right)$, with the second highest levels in Storm $\left(44.4 \mathrm{~g} \mathrm{~N} \mathrm{~kg}^{-1} \mathrm{DM}\right)$, which is also a tetraploid hybrid. This suggests that high $\mathrm{N}$ concentration of the herbage in the grazed horizon is a feature of tetraploid hybrid varieties in swards continuously stocked with sheep.
Concentrations of WSC were highest in 1998 and 1999 for AberDove (Orr et al., 2003), a variety which had been bred for this characteristic. Mean WSC concentrations in that experiment were 116.4 (diploids), 127.5 (tetraploids) and $115 \cdot 1 \mathrm{~g} \mathrm{~kg}^{-1} \mathrm{DM}$ for tetraploid hybrids. Smith et al. (2001) examined WSC concentrations in diploid perennial ryegrass varieties and tetraploids that had been derived from them and concluded that the effect of tetraploidy was dependent on the genetic background of the diploid cultivars. It was not beneficial when it was imposed on cultivars which had the genetic potential for increased WSC accumulation but tetraploidy increased the WSC concentration when derived from a diploid cultivar with standard WSC concentration. Effects of ploidy were also evident in the current experiment (Table 1) where the highest concentration of WSC was measured in the tetraploid variety Twins, which also had high WSC concentrations in the previous experiment. Lee et al. (2001) measured higher lamb liveweight gains when ewes and their single lambs were continuously stocked on AberDove compared with AberElan (lower WSC concentration) and the former variety had a significantly higher in vitro DOMD. Rotationally stocked animals, consuming a higher proportion of pseudostem in their diet, may show a higher level of performance when grazing high WSC varieties because of the greater concentration of WSC in sheath and pseudostem than laminae (McGrath, 1988; Miller, 2001).

In summary, there was evidence of significant differences in some of the morphological and chemical attributes of these contrasting varieties of perennial ryegrass.

\section{Identifying grass morphological and chemical traits correlated with ingestion and rumination}

Glen and Belramo were chosen from the nine diploid varieties available, to represent high and low intake potential, respectively, as measured in 1998 and 1999 (Orr et al., 2003). Similarly, AberExcel and Twins were chosen from the six tetraploid varieties available. Daily DM intake for the variety Belramo in the present experiment was surprisingly high compared with values for 1998 and 1999 (Orr et al., 2003). However, intake rate for the variety Belramo was lower than for the variety Glen in May 2000. In this experiment, the ewes grazing Belramo tended to have fewer meals of longer duration (Table 2) and the DOMD of the herbage, as indicated above, tended to be low. Ewes grazing AberExcel had consistently high daily intakes, both previously and in the current experiment, and this led previously to significantly higher animal performance (Orr et al., 2003) when measured over two 8-month grazing 
seasons. The current experiment was relatively shortterm and so no animal performance data are presented here. Amongst the diploid varieties, Glen tended to have the highest intake rate per minute eating. This suggests two possible approaches which can be used to ensure the acceptability of perennial ryegrass to grazing animals. One strategy is to use prostrate diploid types with a high tiller density; another is to use more-erect tetraploid or tetraploid hybrid types with a lower tiller density. It would seem that both types may have high intake characteristics under continuous stocking management with sheep, depending on the variety chosen. The varieties AberExcel, Glen and AberDove had more leaf above $40 \mathrm{~mm}$ from the root-shoot interface and tended to have higher LAI values than the varieties Belramo and Twins at the same SSH. However, whilst these may be considered to be desirable attributes and there were significant differences in some aspects of sward morphology and chemistry, plant factors examined here were not correlated with intake rate.

\section{Conclusions}

In the UK, most perennial ryegrass varieties are sown in mixtures to give a blend of complementary attributes (e.g. heading dates, life expectancy and ground cover). However, this does not currently include intake characteristics despite the fact that most swards will be grazed for at least part of the year. Daily DM intake was significantly different between the five contrasting perennial ryegrass varieties examined in this study suggesting that there is considerable scope for breeding improved varieties for grazing. Intake rates were not related to the morphological and chemical measures made in this study and other factors need to be explored to identify plant traits that are correlated with herbage intake. These are needed for varieties destined for grazing use, both during the breeding programme and during subsequent evaluation.

\section{Acknowledgments}

We thank Sue Rodway-Dyer and Sue Simmons for assistance with the collection and processing of the data. This work was funded by the UK Department for Environment, Food and Rural Affairs and was carried out in accordance with the welfare standards approved by IGER's Ethical Review Procedure. IGER is supported by the UK Biotechnology and Biological Sciences Research Council.

\section{References}

BARTHRAM G.T. (1986) Hill Farming Research Organisation, Biennial Report 1984-1985, pp. 29-30.
Barthram G.T. and Grant S.A. (1984) Defoliation of ryegrass-dominated swards by sheep. Grass and Forage Science, 39, 211-219.

Barthram G.T., Elston D.A. and Bolton G.R. (2000) A comparison of three methods for measuring the vertical distribution of herbage mass in grassland. Grass and Forage Science, 55, 193-200.

Baumont R., Prache S., Meuret M. and Morand-Fehr P. (2000) How forage characteristics influence behaviour and intake in small ruminants: a review. Livestock Production Science, 64, 15-28.

Diaz S., Noy-Meir I. and Cabido M. (2001) Can grazing response of herbaceous plants be predicted from simple vegetative traits? Journal of Applied Ecology, 38, 497-508.

Dove H. and Mayes R.W. (1991) The use of plant wax alkanes as marker substances in studies of the nutrition of herbivores: a review. Australian Journal of Agricultural Research, 42, 913-952.

Gautier H., Varlet-Grancher C. and Hazard L. (1999) Tillering responses to the light environment and to defoliation in populations of perennial ryegrass (Lolium perenne L.) selected for contrasting leaf length. Annals of Botany, 83, 423-429.

GENSTAT (1987) GENSTAT 5 Committee Reference Manual. Oxford, UK: Clarendon Press.

GiBв M.J. (1998) Animal grazing/intake terminology and definitions. In: Keane M.G. and O'Riordan E.G. (eds) Pasture Ecology and Animal Intake, Occasional Publication no 3, Proceedings of a Workshop held in Dublin, September 1996, for Concerted Action AIR-CT93-0947, pp.21-37. Brussels: Commission of European Community.

Grant S.A. (1981) Sward components. In: Hodgson J., Baker R.D., Davies A., Laidlaw A.S. and Leaver J.D. (eds), Sward Measurement Handbook, pp.71-92. Reading, UK: British Grassland Society.

Hazard L., De Moraes A., Betin M., Traineau R. and Emile J.-C. (1998) Perennial ryegrass cultivar effects on intake of grazing sheep and feeding value. Annales de Zootechnie, 47, 117-125.

Hodgson J. (1985) The control of herbage intake in the grazing ruminant. Proceedings of the Nutrition Society, 44, 339-346.

Jones D.I.H. and HaYwood M.V. (1975) The effect of pepsin treatment of herbage on the prediction of dry matter digestibility from solubility in fungal cellulase solutions. Journal of the Science of Food and Agriculture, 26, 711-718.

Lee M. R. F., Jones E. L., Moorby J. M., Humphreys M. O., Theodorou M. K., Macrae J. C. and Scollan N. D. (2001) Production responses from lambs grazed on Lolium perenne (L.) selected for an elevated water-soluble carbohydrate concentration. Animal Research, 50, 441-449.

LiU J.Y., BARKer D.J., Sulc R.M. and Jang J.C. (2002) Morphological variation within and between ryegrass cultivars and their mixtures. American Society of Agronomy Annual Meeting, 10-14 November 2002, Indianapolis, IN, USA, Poster 842.

MCGRATH D. (1988) Seasonal variation in the water-soluble carbohydrates of perennial and Italian ryegrass under 
cutting conditions. Irish Journal of Agricultural Research, 27, 131-139.

Miller L.A. (2001) Novel Grass Varieties: Improving Nitrogen Use Efficiency for Milk Production. Ph.D. thesis, Aberystwyth, UK: University of Wales.

Ministry of Agriculture, Fisheries and Food (1998) United Kingdom National List Trials Herbage VCU Procedures. London, UK: Plant Varieties and Seeds Division, MAFF.

National Institute of Agricultural Botany (1998) NIAB Recommended Lists of Grasses and Herbage Legumes, 1998/99. Cambridge, UK: National Institute of Agricultural Botany.

Neuteboom J.H. and Lantinga E.A. (1989) Tillering potential and relationship between leaf and tiller production in perennial ryegrass. Annals of Botany, 63, 265-270.

OrR R.J., Harvey A., Kelly C.L. and Penning P.D. (1997) Bite dimensions and grazing severity for cattle and sheep. Proceedings of the Fifth British Grassland Society Research Meeting, Seale Hayne, UK, September, 1997, pp. 185-186. Reading, UK: British Grassland Society.

OrR R.J., MARTyn T.M. and Clements R.O. (2001) Evaluation of perennial ryegrass varieties under frequent cutting or continuous stocking with sheep. Plant Varieties and Seeds, 14, 181-199.

Orr R.J., Cook J.E., Champion R.A., Penning P.D. and Rook A.J. (2003) Intake characteristics of perennial ryegrass varieties when grazed by sheep under continuous stocking management. Euphytica, 134, 247-260.

ORR R.J., RUTTER S.M., YARROW N.H., CHAMPION R.A. and Rook A.J. (2004) Changes in ingestive behaviour of yearling dairy heifers due to changes in sward state during grazing down of rotationally-stocked ryegrass or white clover pastures. Applied Animal Behaviour Science, 87, 205-222.

PArsons A.J. (1984) Guidelines for management of continuously stocked swards. Grass Farmer no 17, pp. 5-9. Reading, UK: British Grassland Society.

Penning P.D., Parsons A.J., OrR R.J. and Treacher T.T. (1991) Intake and behaviour responses by sheep to changes in sward characteristics under continuous stocking. Grass and Forage Science, 46, 15-28.
Penning P.D., Parsons A.J., Newman J.A., OrR R.J. and Harvey A. (1993) The effects of group size on grazing time in sheep. Applied Animal Behaviour Science, 37, 101-109.

Rook A.J. and Penning P.D. (1991) Synchronisation of eating, ruminating and idling activity by grazing sheep. Applied Animal Behaviour Science, 32, 157-166.

RUTTER S.M. (2000) GRAZE: a program to analyze recordings of the jaw movements of ruminants. Behaviour Research Methods, Instruments $\theta$ Computers, 32, 86-92.

Rutter S.M., Champion R.A. and Penning P.D. (1997) An automatic system to record foraging behaviour in freeranging ruminants. Applied Animal Behaviour Science, 54, $185-195$.

Schulte R.P.O. and Lantinga E.A. (2002) Mechanistic simulation of the vertical structure of mixed swards. Ecological Modeling, 149, 229-246.

Smith K.F., Simpson R.J., Culvenor R.A., Humphreys M.O., Prud'HOMme M.P. and Oram R.N. (2001) The effects of ploidy and a phenotype conferring a high water-soluble carbohydrate concentration on carbohydrate accumulation, nutritive value and morphology of perennial ryegrass (Lolium perenne L.). Journal of Agricultural Science, Cambridge, 136, 65-74.

STONE B.A. (1994) Prospects for improving the nutritivevalue of temperate, perennial pasture grasses. New Zealand Journal of Agricultural Research, 37, 349-363.

Swift G., Vipond J.E., Mcclelland T.H., Cleland A.T., Milne J.A. and Hunter E.A. (1993) A comparison of diploid and tetraploid perennial ryegrass and tetraploid ryegrass/ white clover swards under continuous sheep stocking at controlled sward heights. 1. Sward characteristics. Grass and Forage Science, 48, 279-289.

Tecator (1987) Tecator application note 02.18, AN 86/87. Determination of Kjeldahl nitrogen content and Kjeldahl System 1030. Thornbury, Bristol: Tecator Ltd.

THomas T.A. (1977) An automated procedure for the determination of soluble carbohydrates in herbage. Journal of the Science of Food and Agriculture, 28, 639-642.

WARren Wilson J. (1963) Estimation of foliage denseness and foliage angle by inclined point quadrats. Australian Journal of Botany, 11, 95-105. 